\title{
Evolution of genetic variation for selected traits in successive breeding populations of maritime pine
}

\author{
L Bouffier, A Raffin and A Kremer \\ INRA, UMR1202 Biodiversity Genes and Communities, Cestas, France
}

\begin{abstract}
Directional selection impacts a trait distribution by shifting its mean and reducing its variance. The change of variance is of major importance as the response to selection in subsequent generations is highly dependent of the genetic variability available in the population. In this contribution, evolution of genetic variation was investigated through the first breeding populations of the French maritime pine (Pinus pinaster Ait.) breeding program. We considered three populations: P0 (the forest where plus trees were initially selected), G0 (the plus tree population) and $\mathrm{G} 1$ (the population composed of trees selected in the progenies of G0). Analyses focused on the following selected traits: total height $(H)$, girth at $1.30 \mathrm{~m}(D)$ and stem deviation to verticality $(S)$. More than 150000 trees
\end{abstract}

from 25 tests of three distinct populations were studied with an individual genetic model. Accurate genetic parameters were obtained by taking all relationships between trees into account. For $H$ and $D$, we found a strong decrease of the genetic variation from P0 to G0 corresponding to the initial selection of plus trees, which constitutes the base population of the breeding program. Then, despite the second step of selection applied, no appreciable evolution arose from comparisons between $\mathrm{G} 0$ and $\mathrm{G} 1$ for these traits. For $S$, the evolution is less significant as phenotypic variation slightly increased, possibly due to changes of silvicultural practices. Heredity (2008) 101, 156-165; doi:10.1038/hdy.2008.41; published online 4 June 2008

Keywords: Pinus pinaster Ait.; genetic variation; correlation; individual model; evolution; breeding population

\section{Introduction}

The genetic variation of a population is the key factor in determining its response to natural or artificial selection and thus its evolutionary potential. In the present work, we intended to monitor the changes of the genetic variance as a result of directional selection conducted in breeding populations of maritime pine (Pinus pinaster Ait.), a major forest tree species growing in the southwest of France. Monitoring of genetic variation along breeding populations has been undertaken earlier, but on neutral traits in Sitka spruce (Chaisurisri and El-Kassaby, 1994) and in Douglas-fir (El-Kassaby and Ritland, 1996). In contrast to these earlier investigations, our study focuses on traits that underwent selection, hence on genetic variance and not on heterozygosity.

Many analytical analyses and simulations predict the evolution of genetic variance of a selected trait (Bulmer, 1971; Van der Werf and Boer, 1990; Verrier et al., 1991; De Rochambeau et al., 2000). Selection is expected to rapidly reduce the genetic variation, which then stabilizes except in small populations where the erosion of variation continues due to genetic drift and inbreeding. However, many hypotheses underlie these models and few studies have been carried out on real populations under selection (Sorensen and Hill, 1982; Meyer and Hill, 1991; Dupont-Nivet et al., 2001). Dupont-Nivet et al. (2001) observed a strong decrease of genetic variation in

Correspondence: Dr A Kremer, INRA, UMR1202 Biodiversity Genes and Communities, BIOGECO, 69 Route d'Arcachon, Cestas 33612, France.

E-mail:antoine.kremer@pierroton.inra.fr

Received 26 October 2007; revised 2 April 2008; accepted 15 April 2008; published online 4 June 2008 the two first generations of a snail population undergoing selection followed by an equilibrium phase. Meyer and Hill (1991) reported a reduction of genetic variation during 23 generations in a population of mice selected for food intake. They concluded that the evolution of allele frequencies played a major role in that trend. Sorensen and Hill (1982) studied populations of Drosophila and found various patterns for the evolution of genetic variation according to the initial allele frequencies. The evolution of variability thus appears to depend both on the population considered and on the genetic basis of the trait studied.

This paper examines the evolution of genetic variation of the selected traits and their correlations in three successive populations of the French maritime pine breeding program.

Maritime pine (P. pinaster Ait.) represents one million hectares of cultivated forest in Aquitaine (southwestern France). A breeding program has been implemented since the early 1960s (Durel, 1992; GIS, 2002) using a recurrent selection scheme that consists of successive cycles of selection of candidate trees and their crossings (Zobel and Talbert, 1984). The dual goals of the program have been to (1) obtain genetic gain in growth and stem straightness and (2) preserve diversity in the breeding populations. The former goal was achieved since an improvement of $15 \%$ for volume and form was observed in the first varieties compared to unimproved material. Today genetic gains amount to $30 \%$ in the most recent varieties (GIS, 2002). The achievement of the latter goal was less studied but it is considered essential because it allows for future gains and for the incorporation of new selection criteria. 
Genetic variation is estimated for the selected traits based on the 'individual model' (Gwaze et al., 2002), also called 'animal model' as it was first developed in the context of livestock breeding programs (Kennedy et al., 1988). Its adaptation to trees was implemented as breeding populations are moving into advanced generations (Kerr, 1998). The individual model is adapted from the mixed model (Henderson, 1975). This methodology takes into account all the pedigree information to accurately estimate both the genetic parameters of the base population and the breeding values of all genotypes by restricted maximum likelihood (REML). Advantages of the individual model compared to the more traditional least-squares analysis were outlined by Lynch and Walsh (1998). First, as fixed and random effects are estimated simultaneously, the precision of estimates of environmental and genetic main effects is increased. Second, the individual model is better suited to unbalanced data that are frequent in the case of tree-breeding populations, due to unpredictable mortality in long-living species. Third, the method takes into account phenotypic values of related individuals over multiple generations and multiple progeny tests, hence increasing the number of phenotypic predictors and diversifying the genetic relatedness among trees. Finally, the individual model accounts for selection provided that all information used in selection is included in the analysis.

Durel et al. (1998) were among the first to estimate genetic parameters in a tree population with the individual model. In their study, genetic parameters were computed in an overall analysis across seven generations of apple trees. As for forest trees, the method is now widely used in the radiata pine breeding program to rank genotypes within and across generations (Jayawickrama and Carson, 2000). Other studies have also used the individual tree genetic model on more limited data sets (Gwaze et al., 2001, 2002; Dutkowski et al., 2002; Klapste et al., 2007). In the present study, we apply the individual model to monitor the changes of genetic variation and correlation over three successive populations for traits that underwent repeated directional selection.

\section{Materials and methods}

\section{Breeding populations and progeny tests}

For the sake of clarity, the different populations of the maritime pine breeding program are defined as follows (Figure 1):

(i) P0 population is the Landes population that has proven to be the best adapted maritime pine provenance for southwestern France (Illy, 1966). Field tests comparing different geographic seed sources, established as early as 1930, clearly showed that the local provenance exhibited the highest survival and growth potentials. Overall the whole Landes forest covers about one million hectares, with no significant population or ecotypic differentiation (Baradat and Marpeau-Bezard, 1988).

(ii) G0 population is the subset of 635 plus trees that is trees phenotypically selected during the 1960s within the population P0, of which a sample of 320 were used in this study. During approximately 10 years, adult stands in the Landes forest were visited

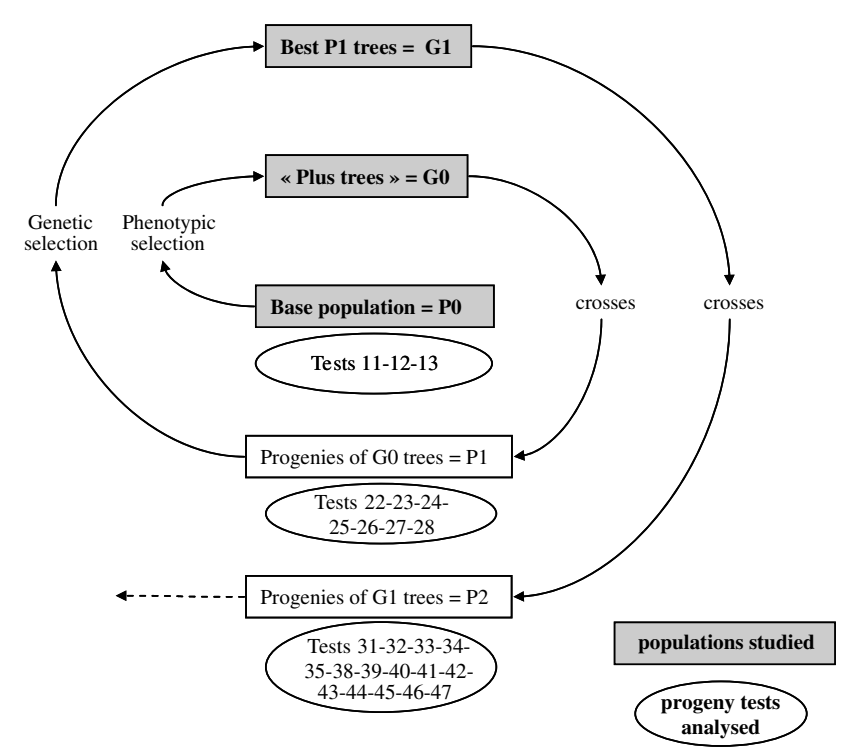

Figure 1 Breeding populations of the French maritime pine breeding program and progeny tests studied (mating designs are explained in more details in Table 1 ).

and outstanding trees in regard to stem volume and straightness were mapped and recorded by using a phenotypic index of selection. Details of the selection procedure are available in Illy (1966).

(iii) P1 population gathers all the progenies obtained in the subsequent improvement steps by crosses between G0 trees. The 635 G0 trees were grafted as clonal archives and subsequently crossed using various mating schemes (polycross, factorial or nested designs).

(iv) G1 population is the new breeding population of about 2600 trees, individually selected within P1. Index selection combining growth and straightness traits was achieved in the P1 progenies, using family and individual values as phenotypic predictors of the breeding value of selection candidates. About $5 \%$ of the P1 trees were selected to build G1 population.

(v) P2 population gathers all progenies obtained by crossing G1 trees following the recurrent strategy of the breeding scheme. The 2600 trees of G1 were crossed using different mating designs (mainly polycross and nested mating designs).

Our analysis focuses on the following three populations: the original population (P0) and the two breeding populations obtained after a selection step (G0 and G1) because their variation can be accurately estimated with the subsequent progeny tests. We compiled data obtained from 25 progeny tests allowing to estimate the genetic variance for the selected traits: three progeny tests established from unselected seeds collected throughout southwest France forest (to estimate the genetic variance in $\mathrm{P} 0$ ), seven progeny tests from P1 population and fifteen progeny tests from P2 population. They correspond to different mating designs (open pollination, factorial, nested design and polycross) and each progeny test comprises on average 135 progenies and 9000 trees (Table 1). From here onwards, 'progeny test' will be called 'test'. The experimental designs are 
Table 1 Test features

\begin{tabular}{|c|c|c|c|c|c|c|c|c|c|c|c|}
\hline Population & Code & Design & Progenies & Trees & Block & $\begin{array}{l}\text { Trees per } \\
\quad \text { plot }\end{array}$ & $\begin{array}{c}\text { Plantation } \\
\text { year }\end{array}$ & $\begin{array}{l}\text { Measurement } \\
\text { age }\end{array}$ & $\begin{array}{l}\text { Height } \\
\text { mean }\end{array}$ & $\begin{array}{l}\text { Girth } \\
\text { mean }\end{array}$ & $\begin{array}{c}\text { Deviation to } \\
\text { verticality mean }\end{array}$ \\
\hline \multirow[t]{3}{*}{ P0 } & 11 & Open pollination & 53 & 1430 & 5 & $3-20$ & 1972 & 8 & 437.5 & 29.2 & 13.2 \\
\hline & 12 & Open pollination & 50 & 1288 & 5 & $8-12$ & 1973 & 10 & 661.9 & 33.1 & 10.0 \\
\hline & 13 & Open pollination & 72 & 3388 & 5 & $3-19$ & 1974 & 10 & 721.0 & 33.6 & 11.0 \\
\hline \multirow[t]{7}{*}{ G0 } & 22 & Open pollination & 56 & 15040 & 90 & 10 & 1965 & 7 & 632.5 & - & - \\
\hline & 23 & Factorial & 144 & 16420 & 48 & $4-12$ & 1968 & 7 & 490.1 & - & - \\
\hline & 24 & Factorial & 169 & 49769 & 8 & 9 & 1969 & 9 & 678.8 & - & - \\
\hline & 25 & Polycross & 261 & 21663 & 50 & $3-9$ & 1975 & 8 & 583.4 & 31.0 & - \\
\hline & 26 & Nested design & 236 & 11745 & 110 & 4 & 1976 & 9 & 654.5 & 30.7 & 7.7 \\
\hline & 27 & Nested design & 75 & 3465 & 33 & 4 & 1977 & 10 & 707.0 & - & 8.0 \\
\hline & 28 & Nested design & 76 & 4132 & 76 & 8 & 1978 & 10 & 711.0 & - & 9.4 \\
\hline \multirow{15}{*}{ G1 } & 31 & Nested design & 72 & 5598 & 68 & 1 & 1981 & 8 & 572.0 & 26.1 & 4.3 \\
\hline & 32 & Nested design & 28 & 2777 & 97 & 1 & 1982 & 12 & 737.8 & 30.6 & - \\
\hline & 33 & Nested design & 157 & 14728 & 50 & 1 & 1985 & 12 & 920.6 & 43.3 & - \\
\hline & 34 & Nested design & 66 & 3966 & 72 & 1 & 1986 & 13 & 1023.0 & 47.7 & - \\
\hline & 35 & Polycross & 213 & 9188 & 125 & 4 & 1982 & 9 & 764.7 & 33.2 & 6.3 \\
\hline & 38 & Polycross & 129 & 6046 & 5 & 10 & 1992 & 11 & 937.4 & 43.9 & - \\
\hline & 39 & Polycross & 101 & 3535 & 35 & 1 & 1994 & 8 & 644.0 & 37.1 & - \\
\hline & 40 & Polycross & 101 & 3535 & 35 & 1 & 1995 & 8 & 658.3 & 35.6 & - \\
\hline & 41 & Polycross & 101 & 3299 & 35 & 1 & 1995 & 8 & 679.5 & 36.3 & - \\
\hline & 42 & Polycross & 211 & 7420 & 35 & 1 & 1995 & 8 & 766.8 & 40.1 & - \\
\hline & 43 & Polycross & 211 & 7455 & 35 & 1 & 1995 & 8 & 633.0 & 33.2 & - \\
\hline & 44 & Polycross & 211 & 7355 & 35 & 1 & 1995 & 8 & 695.7 & 36.4 & - \\
\hline & 45 & Polycross & 197 & 6895 & 35 & 1 & 1996 & 8 & 539.8 & 30.5 & - \\
\hline & 46 & Polycross & 197 & 5495 & 35 & 1 & 1996 & 8 & 644.7 & 32.9 & - \\
\hline & 47 & Polycross & 197 & 6160 & 35 & 1 & 1996 & 8 & 731.5 & 41.3 & - \\
\hline
\end{tabular}


either complete or incomplete blocks with plot sizes varying between 1 to 10 trees depending on the test considered. A 'block' is a test subdivision comprising several 'plots', each consisting of one progeny and spreads over homogeneous site conditions. A block is complete when it comprises all progenies, it is incomplete when it contains only a subset of progenies.

\section{Measurements}

Two growth traits-total height $(H)$ and girth at breast height $(D)$-and a trait relative to stem form $(S)$ were measured between 7 and 13 years depending on the test (Table 1). Different assessments were used for $S$ over the years. Thus, we restricted our analysis of $S$ on those tests for which the same assessment was made repeatedly. The assessment consisted of measuring the stem deviation to verticality, as the angle formed by the stem and a virtual vertical axis passing through the base of the stem.

\section{Genetic model}

The individual model was used to subdivide the phenotypic value of each tree in its genetic and environmental components. As both environmental and genetic effects are computed simultaneously, the best linear unbiased predictor of the genotypes was obtained and the genetic parameters of the base population (that is highest ancestors registered) were estimated (Lynch and Walsh, 1998).

It is important to note that the genetic variation estimated with an individual model depends on the pedigree considered. When the complete multigenerational relationship matrix is considered, genetic parameters of the base population are estimated. To obtain genetic parameters of an advance population ' $t$ ', only the relationship matrix computed from all individuals up to that ancestor population must be kept. The population ' $t$ ' is thus assumed to be the base population (Sorensen and Kennedy, 1984; Meyer and Hill, 1991).

The following mixed model was considered:

$$
y=X \cdot b+Z_{1} \cdot a+Z_{2} \cdot v+e
$$

where $y$ is the vector of observations, $b$ is the vector of fixed effects: test and 'block (test)', $a$ is the vector of genetic effect: individual additive genetic values, $v$ is the vector of plot effect: 'block(test) $\times$ progeny', $e$ is the vector of residuals, $X, Z_{1}$ and $Z_{2}$ are the incidence matrices linking observations to the effects.

No 'progeny $\times$ test' interactions were considered as only few progenies were common to different tests. Furthermore it has been shown that this effect is minor in the Landes area (Bouffier, 2007).

The random effects fit a normal distribution whose parameters were

$$
E\left[\begin{array}{l}
a \\
v \\
e
\end{array}\right]=\left[\begin{array}{l}
0 \\
0 \\
0
\end{array}\right] \text { and } \operatorname{Var}\left[\begin{array}{l}
a \\
v \\
e
\end{array}\right]=\left[\begin{array}{ccc}
G & 0 & 0 \\
0 & H & 0 \\
0 & 0 & R
\end{array}\right]
$$

The variance-covariance matrices were defined as follows:

$$
G=A \cdot \sigma_{\mathrm{A}}^{2} ; \quad H=I \cdot \sigma_{\mathrm{v}}^{2} ; \quad R=I \cdot \sigma_{\mathrm{e}}^{2}
$$

where is $A$ the additive genetic relationship matrix ( $A$ was computed from a pedigree file that takes into account all the relationships between individuals).
I the identity matrix, $\sigma_{A}^{2}$ the additive genetic variance, $\sigma_{v}^{2}$ the plot variance and $\sigma_{e}^{2}$ the residual variance.

The estimates of the fixed and random effects were obtained by solving Henderson's mixed model equations (Henderson, 1975) with the REML method using the ASReml software (Gilmour et al., 2002).

As the variances are assumed to be independent, the phenotypic variance $\sigma_{\mathrm{P}}^{2}$ is expressed as follows:

$$
\sigma_{\mathrm{P}}^{2}=\sigma_{\mathrm{A}}^{2}+\sigma_{\mathrm{v}}^{2}+\sigma_{\mathrm{e}}^{2}
$$

\section{Variation parameters}

Univariate analyses were performed for estimating genetic and phenotypic variation. The variation of the selected traits- $H, D$ and $S$-was first expressed by two widely used standardized assessments: narrow-sense heritability $\left(h^{2}\right)$ and coefficient of additive genetic variation $\left(\mathrm{CV}_{\mathrm{A}}\right)$. For comparative purposes, Houle (1991) showed that genetic variance is more appropriately standardized by the trait mean $\left(\mathrm{CV}_{\mathrm{A}}\right)$ than by the phenotypic variance $\left(h^{2}\right)$, and that heritability is rather useful for making predictions about the absolute response to selection, and $\mathrm{CV}_{\mathrm{A}}$ for assessing genetic variation. In this study, we used both parameters and we also included the phenotypic coefficient of variation $\left(C V_{P}\right)$. As our study is an overall analysis across many experimental designs established over the past 40 years, assessments of $\mathrm{CV}_{\mathrm{P}}$ allow us to check for major environmental sources of variation that may have occurred during this period. Heritability and the two coefficients of variation were computed as follows:

$$
h^{2}=\frac{\sigma_{\mathrm{A}}^{2}}{\sigma_{\mathrm{P}}^{2}} ; \quad \mathrm{CV}_{\mathrm{P}}=\frac{\sigma_{\mathrm{P}}}{\bar{x}} ; \quad \mathrm{CV}_{\mathrm{A}}=\frac{\sigma_{\mathrm{A}}}{\bar{x}}
$$

As ASReml also provides the estimated breeding values for each parent genotype, we also computed a coefficient of variation with the breeding values $\left(\mathrm{CV}_{\mathrm{BV}}\right)$ that can be considered as a third estimate of genetic variation:

$$
\mathrm{CV}_{\mathrm{BV}}=\frac{\sigma_{\mathrm{BV}}}{\bar{x}}
$$

\section{Correlation parameters}

For correlation estimates, we considered a bivariate analysis but, because of a lack of convergence for the maximum likelihood under the full model, we decided not to include $Z_{2} \cdot v$ in the model. The use of this simplified model implies that, for correlation estimates, $\sigma_{\AA}^{2}$ includes both additive and the plot variances. The genetic variance is thus biased upwards compared to the full model.

The estimates of phenotypic $\left(r_{\mathrm{P}}\right)$ and additive genetic $\left(r_{\mathrm{G}}\right)$ correlations between pairs of traits were obtained with bivariate analyses. Genetic correlations were also estimated with the breeding values $\left(r_{\mathrm{BV}}\right)$ using Pearson's correlation.

\section{Standard errors and statistical tests}

The standard errors of $h^{2}, \sigma_{A}^{2}, \sigma_{\mathrm{P}}^{2}, r_{\mathrm{P}}$ and $r_{\mathrm{G}}$ were calculated with ASReml using a standard Taylor series approximation (Gilmour et al., 2002) and those of $C V_{P}$, $\mathrm{CV}_{\mathrm{A}}$ and $r_{\mathrm{BV}}$ were estimated with the approximation proposed by Lynch and Walsh (1998).

In the following analyses, two estimates $x_{1}$ and $x_{2}$ associated with standard errors $\sigma_{1}$ and $\sigma_{2}$ were 
Table 2 Methods to estimate variability and correlations in multigenerational populations using the individual model

\begin{tabular}{|c|c|c|c|c|c|c|c|}
\hline \multicolumn{2}{|c|}{ Analysis } & \multicolumn{3}{|c|}{ Variability } & \multicolumn{3}{|c|}{ Correlations } \\
\hline Data analysed & $\begin{array}{l}\text { Pedigree } \\
\text { considered }\end{array}$ & $\begin{array}{l}h^{2} \text { and } C V_{A} \\
\text { estimated }\end{array}$ & $\begin{array}{l}C V_{B V} \\
\text { estimated }\end{array}$ & Results & $\begin{array}{l}\mathrm{r}_{P} \text { and } \mathrm{r}_{G} \\
\text { estimated }\end{array}$ & $\begin{array}{l}\mathrm{r}_{B V} \\
\text { estimated }\end{array}$ & Results \\
\hline \multicolumn{8}{|l|}{ Method I } \\
\hline Test 11 & Parent level & P0 & P0 & Figure 2 & P0 & P0 & \multirow[t]{4}{*}{ Figure 3} \\
\hline Test 22 & Parent level & G0 & G0 & & G0 & G0 & \\
\hline Test 31 & Parent level & $\dddot{\mathrm{G} 1}$ & $\dddot{\mathrm{G} 1}$ & & $\dddot{\mathrm{G} 1}$ & $\dddot{G 1}$ & \\
\hline$\cdots$ & $\cdots$ & $\cdots$ & $\cdots$ & & $\cdots$ & $\cdots$ & \\
\hline \multicolumn{8}{|l|}{ Method II } \\
\hline P0 (tests 11-13) & Parent level & P0 & $\mathrm{P} 0$ & Figure 2; Table 3 & $\mathrm{P} 0$ & P0 & \multirow[t]{3}{*}{$\begin{array}{l}\text { Figure 3; } \\
\text { Table 4 }\end{array}$} \\
\hline P1 (tests 22-28) & Parent level & G0 & G0 & & G0 & G0 & \\
\hline P2 (tests 31-47) & Parent level & G1 & G1 & & G1 & G1 & \\
\hline \multicolumn{8}{|l|}{ Method III } \\
\hline $\begin{array}{l}\text { P1 and P2 } \\
\text { (tests 22-47) }\end{array}$ & $\begin{array}{l}\text { All relationships } \\
\text { between individuals }\end{array}$ & G0 & G0 and G1 & Table 3 & G0 & G0 and G1 & Table 4 \\
\hline
\end{tabular}

Abbreviations: $\mathrm{CV}_{\mathrm{A}}$, additive coefficient of variation; $\mathrm{CV}_{\mathrm{BV}}$, coefficient of variation of the breeding values; $r_{\mathrm{P}}$, phenotypic correlation; $r_{\mathrm{G}}$, genetic correlation; $r_{\mathrm{BV}}$, correlations estimated with breeding values.

considered significantly different if the statistical test

$$
u=\frac{\left|x_{1}-x_{2}\right|}{\sqrt{\sigma_{1}^{2}+\sigma_{2}^{2}}},
$$

which is assumed to be distributed as a standard normal law, was higher than 1.96 (bilateral significance level of $5 \%$ ).

Methods used to estimate parameters of genetic variation Three methods were carried out to estimate the variation of the selected traits (Table 2). All of them take advantage of the individual model previously described but are based on different data sets and refer to different populations.

Method I: Each test was analysed individually considering the genetic relationship matrix truncated to the parent level. We thereby obtained an estimation of the genetic variation within the parental population. For example, the analysis of a test from the P1 population will provide an estimation of the G0 genetic parameters.

Method II: Tests belonging to the same population were analysed all together (and not individually as per Method I) considering also the genetic relationship matrix truncated to the parent level. Thus, estimates of genetic variation within $\mathrm{P0}$ (G0 and G1, respectively) were obtained from data of tests 11-13 (22-28, 31-47, respectively). Similarly, breeding values of P0, G0 and G1 trees and their coefficient of variation $\left(\mathrm{CV}_{\mathrm{BV}}\right)$ can be estimated from their progenies.

Method III: A global analysis was performed with all the tests except tests 11-13 because no pedigree connection existed between the population P0 and the following ones. The pedigree considered took into account the complete multigeneration genetic relationships. We thus obtained another estimate for the G0 genetic parameters (considered, in this analysis, as the base population) and for $\mathrm{CV}_{\mathrm{BV}}$ of populations $\mathrm{G} 0$ and G1.

The same three methods were used to estimate correlations between the selected traits (Table 2).

\section{Results}

\section{Analyses per test (Method I)}

Figure 2 displays the results of each single test analysis for $H, D$ and $S$. There is a wide range of variation of each parameter $\left(h^{2}, \mathrm{CV}_{\mathrm{A}}\right.$ and $\left.\mathrm{CV}_{\mathrm{P}}\right)$ among tests within a population. For example, $\mathrm{CV}_{\mathrm{A}}$ of $D$ (Figure $2 \mathrm{~b} 2$ ) varies between 5.1 to $14.1 \%$ (mean standard errors is $0.9 \%$ ) among the different tests of population G1. For a given test and trait, $\mathrm{CV}_{\mathrm{BV}}$ is always lower than $\mathrm{CV}_{\mathrm{A}}$.

In most of the tests, $H$ appears to be slightly more heritable and exhibits a lower genetic coefficient of variation than $D$. The phenotypic coefficient of variation is clearly lower for $H$ (between 8.4 and $18.3 \%$ ) than $D$ (between 14.5 and $34.7 \%$ ). Heritability of $S$ is about of the same magnitude than $H$ or $D$ but the genetic and phenotypic coefficients of variation are much higher $\left(\mathrm{CV}_{\mathrm{A}}\right.$ superior to $20 \%$ and $\mathrm{CV}_{\mathrm{P}}$ superior to $\left.50 \%\right)$.

Variation parameters of G0 and G1 are more accurate (that is lower standard errors) than those of P0 as they are estimated with tests implying more progenies.

Correlations were estimated for each single test (Figure 3). Note that $S$ is the deviation to verticality, thus a positive correlation between $S$ and a growth trait $(H$ or $D)$ means that straightness is unfavourably correlated with growth. Phenotypic correlations are high between $H$ and $D$ and moderate between $S$ and growth traits. Genetic correlations are higher than the phenotypic ones albeit estimated with a larger standard error. As for the genetic variance, there is a wide range of variation of correlations among the different tests. 


\section{a1}

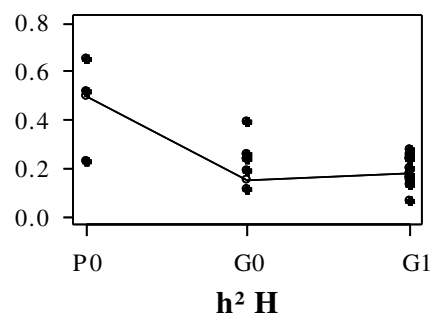

a2

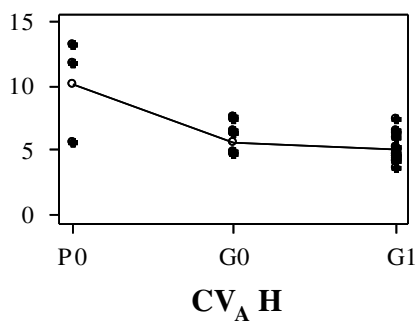

a3

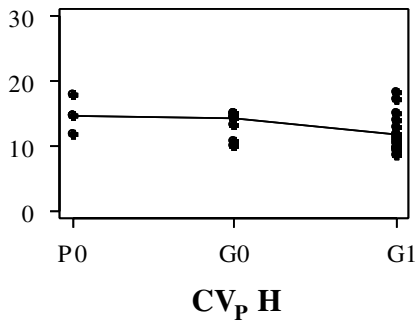

b1

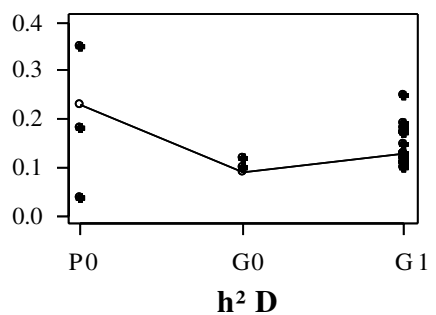

b2

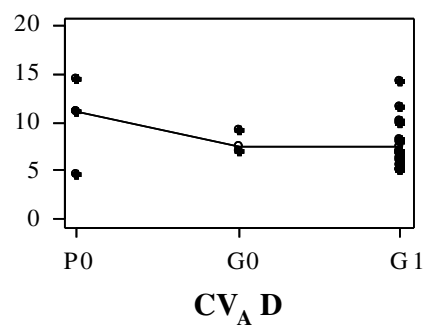

b3

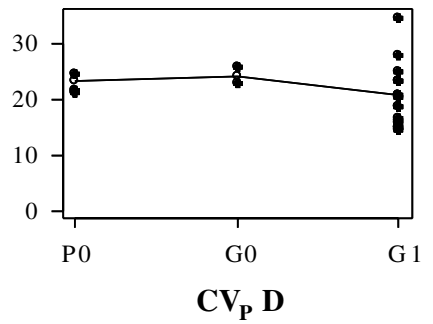

c1

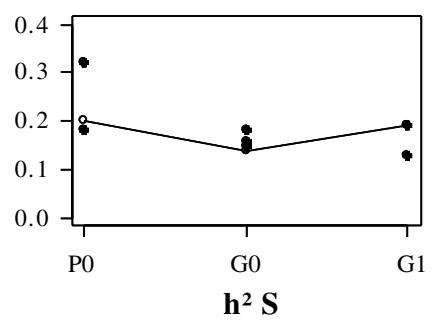

c2

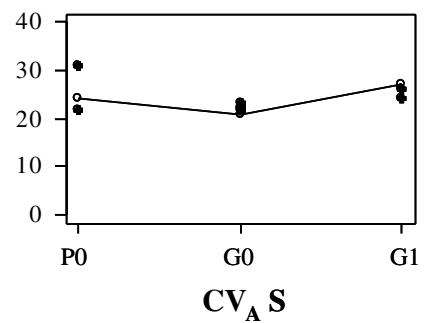

c3

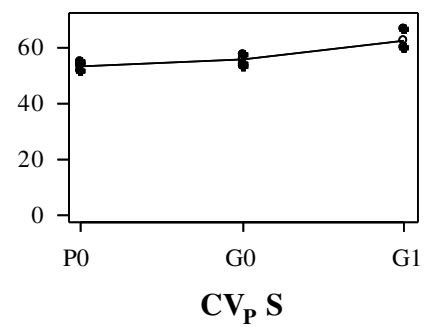

$\left(\mathrm{H}=\right.$ total height $; \mathrm{D}=$ girth at breast height $; \mathrm{S}=$ stem deviation to verticality $; \mathrm{h}^{2}=$ heritability $; \mathrm{CV}_{\mathrm{A}}=$ additive coefficient of variation $; \mathrm{CV}_{\mathrm{P}}=$ phenotypic coefficient of variation)

Figure 2 Genetic parameters in the progeny tests studied from populations P0, G0 and G1. Estimations are done considering the genetic relationship matrix truncated to the parent level. Each test value (Method I) is represented by a dot and the populations values (Method II) are linked by a line.

\section{Analyses per population (Method II)}

Variation parameters estimated for each entire population with the genetic relationship matrix truncated to the parent level are presented in Figure 2 (values linked by a line) and Table 3 . For each population, a large set of data was analysed: 6105 trees were considered for P0, 67223 trees for G0 and 86582 trees for G1. As a consequence, variation parameters were estimated with low standard errors compared to the estimates from 'Method I'.

The evolution of genetic variation over breeding populations is similar for $H$ and $D . C_{\mathrm{A}}$ decreases between P0 and G0 (from 10.2 to $5.6 \%$ for $H$, and from 11.1 to $7.4 \%$ for $D$ ) then remains constant between G0 and G1. Likewise $\mathrm{CV}_{\mathrm{BV}}$ of these two traits decreases substantially from P0 to G0 (from 8.2 to $5.3 \%$ for $H$, and from 8.0 to $5.5 \%$ for $D$ ) then slightly from G0 to G1 (from 5.3 to $4.1 \%$ for $H$, and from 5.5 to $4.1 \%$ for $D$ ). Although $\mathrm{CV}_{\mathrm{P}}$ is rather stable from $\mathrm{P0}$ to $\mathrm{G} 0$, it tends to decrease between G0 and G1. Heritability, which follows the same pattern than $\mathrm{CV}_{\mathrm{A}}$ from $\mathrm{P0}$ to $\mathrm{G} 0$, slightly increases from G0 to G1.

The evolution of genetic parameters for $S$ is similar between P0 and G0 but the trend is weaker and not significant: $\mathrm{CV}_{\mathrm{A}}$ decreases from 24.1 to $20.9 \%$ and $\mathrm{CV}_{\mathrm{BV}}$ from 18.0 to $17.0 \%$. Then an increase is observed between G0 and G1 (from 20.9 to $26.9 \%$ for $\mathrm{CV}_{\mathrm{A}}$ and from 17.0 to $20.2 \%$ for $\left.C V_{B V}\right) . C_{P}$ slightly increases from P0 to $G 1$.

Method II was also used to estimate the correlations between the three selected traits (Figure 3; Table 4). No strong pattern can be observed in regard to the standard errors. Nevertheless the genetic correlation between $H$ and $D$ is slightly lower in breeding populations G0 and G1 than in P0. There is no significant change of the correlation between $H$ and $S$, and between $D$ and $S$ (Table 4).

\section{Analysis of the whole data (Method III)}

Method III provides an overall estimation of the genetic variation in G0 across all populations and tests, by taking into account multigeneration genetic relationships. However this method does not allow the estimation of parameters of $\mathrm{P} 0$, as trees from tests 11 to 13 are not genetically related to trees of subsequent populations. Method III is based on a very large sample of trees: for example, 153805 trees were considered to estimate heritability of $H$. Stem deviation from verticality $(S)$ exhibits greater genetic variation (both in terms of 
a1

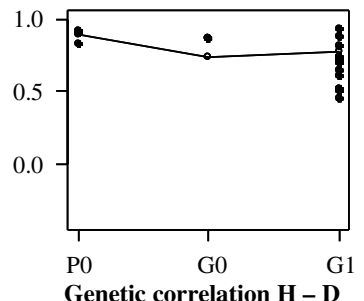

a2

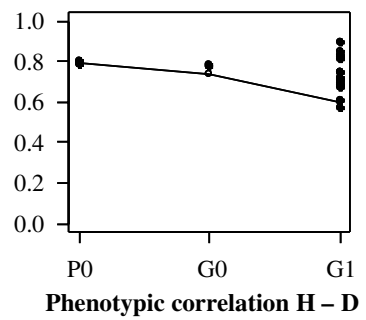

b1

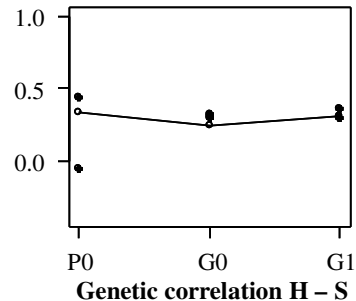

b2

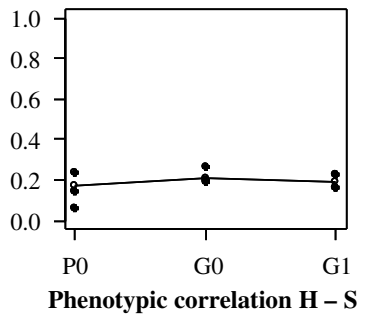

c1

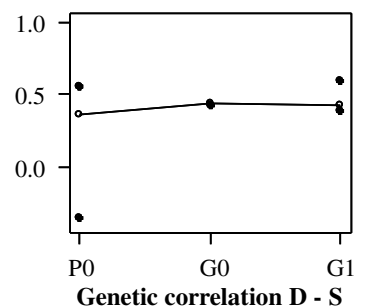

c2

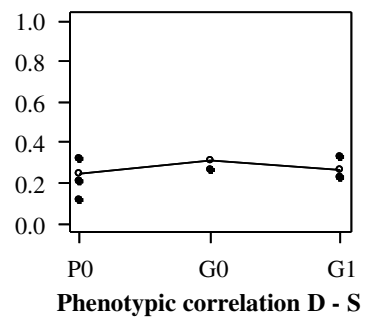

( $\mathrm{H}=$ total height $; \mathrm{D}=$ girth at breast height $; \mathrm{S}=$ stem deviation to verticality)

Figure 3 Correlations in the progeny tests studied from populations P0, G0 and G1. Estimations are done considering the genetic relationship matrix truncated to the parent level. Each test value (Method I) is represented by a dot and the populations values (Method II) are linked by a line.

Table 3 Variability estimated per population considering either the pedigree relationships up to the parent level (Method II) or the all pedigree relationships (standard errors given in brackets)

\begin{tabular}{|c|c|c|c|c|c|}
\hline & \multicolumn{3}{|c|}{ Method II } & \multicolumn{2}{|c|}{ Method III } \\
\hline & P0 & G0 & G1 & G0 & G1 \\
\hline \multicolumn{6}{|l|}{$H$} \\
\hline$h^{2}$ & $0.50(0.08) a$ & $0.15(0.01) b$ & $0.18(0.01) c$ & $0.19(0.01)$ & - \\
\hline $\mathrm{CV}_{\mathrm{A}}$ & $10.2(0.9) a$ & $5.6(0.3) b$ & $5.0(0.2) b$ & $5.5(0.2)$ & - \\
\hline $\mathrm{CV}_{\mathrm{BV}}$ & $8.2(0.4) a$ & $5.3(0.2) b$ & $4.1(0.1) c$ & $5.0(0.2) a^{\prime}$ & $4.4(0.1) b^{\prime}$ \\
\hline $\mathrm{CV}_{\mathrm{P}}$ & $14.5(0.1) a$ & $14.1(0.1) b$ & $11.9(0.0) c$ & $12.6(0.0)$ & - \\
\hline \multicolumn{6}{|l|}{$D$} \\
\hline$h^{2}$ & $0.23(0.05) a$ & $0.09(0.01) b$ & $0.13(0.01) c$ & $0.14(0.01)$ & - \\
\hline $\mathrm{CV}_{\mathrm{A}}$ & $11.1(1.1) a$ & $7.4(0.4) b$ & $7.5(0.2) b$ & $8.1(0.2)$ & - \\
\hline $\mathrm{CV}_{\mathrm{BV}}$ & $8.0(0.4) a$ & $5.5(0.2) b$ & $4.1(0.1) c$ & $5.8(0.2) a^{\prime}$ & $6.2(0.1) a^{\prime}$ \\
\hline$C V_{P}$ & $23.2(0.2) a$ & $24.2(0.1) b$ & $20.9(0.1) c$ & $21.6(0.1)$ & - \\
\hline \multicolumn{6}{|l|}{$S$} \\
\hline$h^{2}$ & $0.20(0.04) a$ & $0.14(0.02) a$ & $0.19(0.02) a$ & $0.16(0.01)$ & - \\
\hline $\mathrm{CV}_{\mathrm{A}}$ & $24.1(2.3) a$ & $20.9(1.3) a$ & $26.9(1.7) b$ & $23.2(1.1)$ & - \\
\hline $\mathrm{CV}_{\mathrm{BV}}$ & $18.0(1.0) a$ & $17.0(0.7) a$ & $20.2(0.8) b$ & $17.2(0.7) a^{\prime}$ & $21.2(0.8) b^{\prime}$ \\
\hline $\mathrm{CV}_{\mathrm{P}}$ & $53.8(0.5) a$ & $55.9(0.4) b$ & $62.5(0.5) c$ & $58.7(0.3)$ & - \\
\hline
\end{tabular}

Abbreviations: $\mathrm{CV}_{\mathrm{A}}$, additive coefficient of variation; $\mathrm{CV}_{\mathrm{BV}}$, coefficient of variation of the breeding values; $\mathrm{CV}_{\mathrm{P}}$, phenotypic coefficient of variation; $D$, girth at breast height; $H$, total height; $h^{2}$, heritability; G0, the plus tree population; G1, the population composed of trees selected in the progenies of G0; P0, the plus tree population; S, stem deviation to verticality.

For a given trait and a given parameter, different letters indicate significant difference between estimates.

heritability and genetic variance) than $H$ or $D$ (Table 3 ). Estimates of variation of G0 are similar between Method III (analysis based on P1 and P2 populations) and Method II (analysis based only on P1 population). However, for $H$ and $D$, the heritability is slightly higher and the phenotypic variation lower when both populations P1 and P2 are considered.

Method III also facilitates the estimation of $\mathrm{CV}_{\mathrm{BV}}$ in $\mathrm{G} 0$ and G1 with the same data set. No strong evolution from G0 to G1 is highlighted: $C_{\mathrm{BV}}$ of $H$ slightly decreases, no significant change is found for $D$ and $C_{\mathrm{BV}}$ of $S$ slightly increases. Thus these results confirm those obtained by Method II.
Correlation estimates among traits in G0 population are very similar between Methods II and III (Table 4). Correlations were also estimated within G0 and G1 trees with the breeding values. Only a slight decrease was observed from G0 to G1 for $H-D$ correlation.

\section{Discussion}

Level of genetic variation for growth traits $(H, D)$ and stem deviation to verticality $(S)$

Our study shows that genetic variation of these traits in natural populations and in the very early breeding 
Table 4 Correlations between selected traits in the successive populations (standard errors given in brackets)

\begin{tabular}{|c|c|c|c|c|c|}
\hline & \multicolumn{3}{|c|}{ Method II } & \multicolumn{2}{|c|}{ Method III } \\
\hline & P0 & G0 & G1 & G0 & G1 \\
\hline \multicolumn{6}{|c|}{ Correlations $H-D$} \\
\hline$r_{\mathrm{P}}$ & $0.79(0.01) a$ & $0.74(0.00) b$ & $0.60(0.00) c$ & $0.73(0.00)$ & - \\
\hline$r_{\mathrm{G}}$ & $0.89(0.01) a$ & $0.73(0.03) b$ & $0.77(0.03) b$ & $0.67(0.02)$ & - \\
\hline$r_{\mathrm{BV}}$ & $0.91(0.03) a$ & $0.81(0.03) b$ & $0.85(0.02) b$ & $0.78(0.04) a^{\prime}$ & $0.68(0.02) b^{\prime}$ \\
\hline \multicolumn{6}{|c|}{ Correlations $H-S$} \\
\hline$r_{\mathrm{P}}$ & $0.17(0.01) a$ & $0.21(0.01) b$ & $0.19(0.01) b$ & $0.20(0.01)$ & - \\
\hline$r_{\mathrm{G}}$ & $0.33(0.11) a$ & $0.24(0.07) a$ & $0.31(0.07) a$ & $0.27(0.05)$ & - \\
\hline$r_{\mathrm{BV}}$ & $0.37(0.07) a$ & $0.23(0.06) a$ & $0.27(0.05) a$ & $0.23(0.06) a^{\prime}$ & $0.32(0.05) a^{\prime}$ \\
\hline \multicolumn{6}{|c|}{ Correlations $D-S$} \\
\hline$r_{\mathrm{P}}$ & $0.25(0.01) a$ & $0.31(0.01) b$ & $0.26(0.01) a$ & $0.29(0.01)$ & - \\
\hline$r_{\mathrm{G}}$ & $0.36(0.12) a$ & $0.44(0.08) a$ & $0.43(0.07) a$ & $0.42(0.05)$ & - \\
\hline$r_{\mathrm{BV}}$ & $0.37(0.07) a$ & $0.27(0.05) a$ & $0.38(0.05) a$ & $0.34(0.05) a^{\prime}$ & $0.47(0.05) a^{\prime}$ \\
\hline
\end{tabular}

Abbreviations: $D$, girth at breast height; $H$, total height; $r_{\mathrm{BV}}$, correlations estimated with breeding values; $r_{\mathrm{G}}$, genetic correlation; $r_{\mathrm{P}}$, phenotypic correlation; S, stem deviation to verticality.

For a given parameter, different letters indicate significant difference between estimates.

populations is moderate (Table 3). Cornelius (1993) compiled genetic parameter $\left(h^{2}\right.$ and $\left.\mathrm{CV}_{\mathrm{A}}\right)$ estimates from 67 published papers, mainly on Pinus species. They were based on experimental designs established with progenies of selected trees from natural populations (corresponding thus to our tests with $\mathrm{P} 1$ trees) and can therefore be compared to our results. Most of the heritability estimates $\left(\mathrm{CV}_{\mathrm{A}}\right)$ of $H$ and $D$ varied between 0.05 and 0.40 (respectively between 5 and 15\%). Results from our individual tests are within this range but our study clearly indicates that estimates can be quite variable across tests, suggesting that they are highly dependent on the sampling of genetic entries and the site conditions (Figure 2). Consequently, many authors have tried to compile data from several tests to estimate the genetic parameters of a population more accurately. The heritability of growth traits of the base population of P. elliottii breeding program (G0 population) varied between 0.12 and 0.16 over a large set of tests (Hodge and White, 1992; Dieters et al., 1995). Jayawickrama (2001) analysed more than 150000 radiata pines to estimate genetic variation of the plus tree population (G0 population): heritability amounted to 0.11 for girth, 0.13 for height and 0.19 for straightness. These three analyses based on large data sets reported low to moderate genotype $\times$ environment interactions. Our estimates for population G0 and G1 are of similar magnitude (Table 3-Method II). As expected, the unselected population P0 displays higher estimates than populations under selection. The high variation across tests (Figure 2) further indicates a need for multiple tests to reliably estimate genetic variation. In this respect, the individual model is a recommended method, as suggested by the decrease of the standard error of variation parameters as we moved from Method I to III (data not shown).

With regard to the comparison of the level of genetic variation among traits, Cornelius (1993) concluded that $H$ is more heritable than $D(0.25$ for the median heritability of height vs 0.19 for diameter), and exhibits higher genetic variance (as shown by the coefficient of genetic variation). Although we draw similar conclusions for heritability ( $h^{2}$ higher for $H$ than for $\left.D\right)$, there is an opposite trend for the coefficients of variation: both $\mathrm{CV}_{\mathrm{A}}$ and $\mathrm{CV}_{\mathrm{P}}$ are higher for $D$ than $H$ (Table 3). Lending support to our result, Gwaze et al. (2001) also observed higher heritability and a lower coefficient of variation for height compared to diameter in $P$. taeda based on an individual tree model. The coefficients of variation of $H$ and $D$ can be compared in our study without corrections because they have the same dimensionality (Houle, 1991).

Genetic parameters of $S$ are more difficult to compare across studies because several different phenotypic assessments were used to assess stem straightness. However, as for other studies (Cornelius, 1993; Jayawickrama, 2001), a higher genetic variation is observed compared to the growth traits (Figure 2; Table 3).

\section{Evolution of the genetic variation of selected traits throughout successive populations}

Regardless of the method used, phenotypic variation shows no clear evolution for $H$ and $D$ from P0 to G0 but decreases slightly from G0 to G1 (Figure 2; Table 3). On the contrary, there is a clear decrease of genetic variation from P0 to G0 and a very minor decrease from G0 to G1. The pattern of genetic variation is consistent among the parameters used $\left(\mathrm{CV}_{\mathrm{A}}\right.$ or $\left.\mathrm{CV}_{\mathrm{BV}}\right)$. Therefore we restrict the discussion to $\mathrm{CV}_{\mathrm{BV}}$ as $C V_{\mathrm{BV}}$ was the only parameter that could be used for comparing genetic variation over breeding populations with Method III. $\mathrm{CV}_{\mathrm{BV}}$ is reduced on average by $35 \%$ for $H$ and by $31 \%$ for $D$ between P0 and G0 (Table 3).

There is still a significant decrease of $\mathrm{CV}_{\mathrm{BV}}$ of growth traits from G0 and G1 according to Method II (by 23\% for $H$ and by $25 \%$ for $D$; see Table 3 ). Yet, according to Method III, the most accurate analysis as it gathers both $\mathrm{P} 1$ and P2 populations, the decrease is weak for $H(12 \%)$ and not significant for $D$ between populations G0 and G1 (Table 3).

In conclusion, although mean values of the two growth traits increased as a result of directional selection from G0 to G1, only a very slight reduction of genetic variation was observed. Similarly, King et al. (1998) reported no change of genetic variation between two breeding 
populations of $P$. radiata equivalent to the ones we referred to as G0 and G1.

Genetic variance of $S$ follows a similar trend across generations albeit less pronounced: there is a nonsignificant decrease from P0 to G0 followed by a slight increase from G0 to G1 (Table 3). The increase from G0 to G1 is unexpected as stem straightness underwent recurrent directional selection like the two other traits. However, silvicultural practices have changed over time, and may have impacted stem straightness more than the other two growth traits. Intensive treatments such as the use of fertilizers and ploughing that became more frequent in recent times may have increased the environmental and genetic variation of traits. This is suggested by the larger increase of the phenotypic variance of $S$ from P0 to G1 (Figure 2; Table 3), in contrast to $H$ and $D$. Under such circumstances, one may suspect that the genetic variance has been impacted as well, blurring the effect of directional artificial selection that we tried to monitor.

Changes of genetic variance in artificial breeding populations may result from either drift effects due to the reduction of population size, or from directional selection. As the pedigree is known over two generations, the 'status number' $\left(N_{\mathrm{S}}\right)$ (Lindgren et al., 1996) can be used to provide an estimate of the population effective size. $N_{S}$ is the number of unrelated and non-inbred genotypes in an ideal panmictic population, which is expected to produce offspring with the same coefficient of inbreeding as the progeny of the considered population following random mating' (Lindgren et al., 1997). On the basis of the pedigree data of the tests considered in this study, the status number of G1 amounts to about 90 that can be compared to the 320 unrelated plus trees of the G0 population analysed here. The estimated decrease of genetic variance at generation ' $t$ ' due to the reduction of population size should amount to $(1-(1 / 2 \mathrm{Ne}))$ of the genetic variance at generation ' $t-1$ ', where $\mathrm{Ne}$ is the effective size (Lynch and Walsh, 1998). Consequently, the reduction of genetic variance due to the reduction of population size remains extremely small, and is therefore most likely to be caused by directional selection.

The evolution of genetic variation in populations undergoing selection was first investigated by Bulmer (1971). By considering a quantitative trait controlled by an infinite number of loci, he subdivided genetic variance $\left(V_{\mathrm{A}}\right)$ into two components: the 'equilibrium genetic variance' also called genic variance (the first term of the following equation) and the 'disequilibrium contribution' (the second term):

$$
V_{\mathrm{A}}=\sum_{i} \operatorname{Var}\left(g_{i}\right)+\sum_{i \neq j} \operatorname{Cov}\left(g_{i}, g_{j}\right)
$$

with $\operatorname{Var}\left(g_{i}\right)$ the variance at the $i$ th locus and $\operatorname{Cov}\left(g_{i}, g_{j}\right)$ the covariance between the $i$ th and the $j$ th loci.

Under this model, Bulmer (1971) showed that directional selection induces a negative disequilibrium contribution, and thus the genetic variance decreases over generations. This effect, known as the 'Bulmer effect', is temporary and the disequilibrium contribution progressively approaches 0 if selection is relaxed. Bulmer (1971) showed with an analytical model that the decrease of genetic variance under selection is high in the first generations and rapidly stabilized. The equilibrium stage occurs when the effects of selection and recombination counterbalance each other. However, the reduction of the genetic variance can be inflated by the reduction of genic variance. Indeed, the genic variance decreases if the trait under selection is determined by a finite number of genes or if small populations are considered (De Rochambeau et al., 2000).

The reduction of genetic variation observed between P0 and G0 is thus mainly explained by the phenotypic selection conducted in the 1960 s to constitute the 'plus' trees population, and may be due to the Bulmer effect. A mass selection was performed throughout the Landes forest, using a procedure that permitted the consideration of a genetic component in the phenotypic superiority of selected trees. The method was based on the standardized value of a candidate tree compared to its 30 immediate neighbours (Illy, 1966), thus taking into account environmental effects. Despite the moderate heritability of the selected traits (from 0.20 to 0.50 ; see Table 3), the extremely high selection rate that was used during the mass selection was sufficient to reduce the genetic variation in the subsequent generation (G0). Illy (1966) reported that 1 tree out of 70000 was selected during this selection step (this estimation is based on the number of trees screened for plus trees selection).

As a genetic selection step was then achieved to build the G1 population from progenies of G0 trees, we also expected a significant decrease of genetic variation for selected traits. However the decrease was much lower or non-significant depending on the method considered. Various hypotheses can be suggested to interpret theses results. First, the accuracy of the analyses may not be able to detect a slight decrease of genetic variation. Second, the selection was performed on three criteria $(H, D$ and $S$ ); therefore the selection intensity for each of them may be more limited and may have been much lower than the selection intensity used during the first stage (from P0 to G0). Third, the equilibrium phase may be achieved after the selection of the plus trees but this hypothesis is unlikely as only one selection step was performed to obtain the population G0.

\section{Level and evolution of the correlations between the selected traits throughout successive populations}

Genetic correlations are highly positive (favourable) between $H$ and $D$, whereas they are slightly positive (unfavourable) between growth traits and stem deviation to verticality (Figure 3; Table 4). Considering both Methods II and III, no consistent pattern in the correlation change was found, except for a slight decrease between P0 and G0 for $H-D$ correlation.

The evolution of genetic correlation was investigated by simulations according to the relative weights of index selection and to the initial variation of the traits (McMillan et al., 1995). If the initial genetic correlation is positive, simulations suggest a decline towards 0 , the rate of change increasing with the heritability of one or both traits. If genetic correlation is negative, there are two contrasting trends: either the correlation increases towards 0 if economic weights are unequal or it declines to -1 if they are equal. The slight change of the $H-D$ correlation observed is in agreement with these simulations. As economic weights of growth traits and straightness are similar, we expect an increase of the $D-S$ correlation through the breeding populations. 
Indeed we found a slight increase for $r_{\mathrm{BV}}$ but it appears non-significant.

\section{Conclusion}

Our results showed that even if the population effective size has been substantially reduced over successive breeding populations, the genetic variance for the selected traits has not followed the same trend. Indeed, after a decrease when selecting for plus trees, the genetic variation remained fairly constant suggesting the possibility to maintain genetic gains over future generations with this recurrent selection strategy.

Lastly we may suppose that genetic variation of unselected traits has been maintained above the level we observed for selected traits. Selection for new criteria could therefore be implemented at the level of G2 without enriching the genetic variation from external genetic resources, provided that genetic correlation between the new criteria and growth or straightness remains low.

\section{Acknowledgements}

We thank Florence Jaffrezic from INRA Jouy-en-Josas for help using the individual model. Plantations were maintained by the members of the GIS 'Pin Maritime du Futur' (FCBA, CRPF, CPFA, ONF, INRA). We also thank the Experimental Unit of INRA for field measurements. This work was supported by funding from the French Ministry of Agriculture and the Région Aquitaine.

\section{References}

Baradat P, Marpeau-Bezard A (1988) Le pin maritime (Pinus pinaster Ait.): biologie et génétique des terpènes pour la connaissance et l'amélioration de l'espèce. PhD thesis, Université Bordeaux I.

Bouffier L (2007) Évolution de la variabilité génétique dans les populations d'amélioration du pin maritime (Pinus pinaster Ait.) et conséquences pour la sélection. PhD thesis, Université Bordeaux.

Bulmer MG (1971). The effect of selection on genetic variability. Am Nat 105: 201-211.

Chaisurisri K, El-Kassaby YA (1994). Genetic diversity in a seed production population vs natural populations of Sitka Spruce. Biodiv Conserv 3: 512-523.

Cornelius J (1993). Heritabilities and additive genetic coefficients of variation in forest trees. Can J For Res 24: 372-379.

De Rochambeau H, Fournet-Hanocq F, Vu Tien Khang J (2000). Measuring and managing genetic variability in small populations. Ann Zootech 49: 77-93.

Dieters MJ, White TL, Hodge GR (1995). Genetic parameter estimates for volume from full-sib tests of slash pine (Pinus elliottii). Can J For Res 25: 1397-1408.

Dupont-Nivet M, Mallard J, Bonnet JC, Blanc JM (2001). Evolution of genetic variability in a population of the edible snail, Helix aspersa Müller, undergoing domestication and short-term selection. Heredity 87: 129-135.

Durel CE (1992). Gain génétiques attendus après sélection sur index en seconde génération d'amélioration du pin maritime. Rev For Fr 44: 341-355.

Durel CE, Laurens F, Fouillet A, Lespinasse Y (1998). Utilization of pedigree information to estimate genetic parameters from large unbalanced data sets in apple. Theor Appl Genet 96: 1077-1085.
Dutkowski GW, Costa e Silva J, Gilmour AR, Lopez GA (2002). Spatial analysis methods for forest genetic trials. Can J For Res 32: 2201-2214.

El-Kassaby YA, Ritland K (1996). Impact of selection and breeding on the genetic diversity in Douglas-fir. Biodiv Conserv 5: 795-813.

Gilmour AR, Gogel BJ, Cullis BR, Welham SJ, Thompson R (2002) ASReml User Guide Release 1.0 VSN International Ltd, Hemel Hempstead, HP1 1ES, UK.

GIS (2002) Genetic Breeding of the Maritime Pine in Aquitaine. GIS Work Report PG edition: Bordeaux.

Gwaze DP, Bridgwater FE, Byram TD, Lowe WJ (2001). Genetic parameter estimates for growth and wood density in Loblolly pine (Pinus taeda L.). For Genet 8: 47-55.

Gwaze DP, Harding KJ, Purnell RC, Bridgewater FE (2002). Optimum selection age for wood density in loblolly pine. Can J For Res 32: 1393-1399.

Henderson CR (1975). Best linear unbiaised estimation and prediction under a selection model. Biometrics 31: 423-447.

Hodge GR, White TL (1992). Genetic parameter estimates for growth traits at different ages in slash pine and some implications for breeding. Silvae Genet 41: 252-262.

Houle D (1991). Comparing evolvability and variability of quantitative traits. Genetics 130: 195-204.

Illy G (1966). Recherches sur l'amélioration génétique du pin maritime. Ann Sci For 23: 757-948.

Jayawickrama KJS (2001). Genetic parameter estimates for radiata pine in New Zealand and New South Wales: a synthesis of results. Silvae Genet 50: 45-53.

Jayawickrama KJS, Carson MJ (2000). A breeding strategy for the New Zealand radiata pine breeding cooperative. Silvae Genet 49: 82-90.

Kennedy BW, Schaeffer LR, Sorensen DA (1988). Genetic properties of animal models. J Dairy Sci 71: 17-26.

Kerr RJ (1998). Asymptotic rates of response from forest tree breeding strategies using best linear unbiased prediction. Theor Appl Genet 96: 484-493.

King JN, Carson MJ, Johnson GR (1998). Analysis of disconnected diallel mating designs: II-results from a third generation progeny test of the New Zealand radiata pine improvement programme. Silvae Genet 47: 80-87.

Klapste J, Lstiburek M, Kobliha J (2007). Initial evaluation of half-sib progenies of Norway spruce using the best linear unbiased prediction. J For Sci 53: 41-46.

Lindgren D, Gea L, Jefferson P (1996). Loss of genetic diversity monitored by status number. Silvae Genet 45: 52-59.

Lindgren D, Gea LD, Jefferson PA (1997). Status number for measuring genetic diversity. For Genet 4: 69-76.

Lynch M, Walsh B (1998). Genetics and Analysis of Quantitative Traits. Sinauer Associates: Sunderland, Massachussetts.

McMillan I, Fairfull RW, Friars GW, Quinton M (1995). The effect of simultaneous selection on the genetic correlation. Theor Appl Genet 91: 776-779.

Meyer K, Hill WG (1991). Mixed model analysis of a selection experiment for food intake mice. Genet Res 57: 71-81.

Sorensen DA, Hill WG (1982). Effect of short term directional selection on genetic variability: experiments with Drosophila melanogaster. Heredity 48: 27-33.

Sorensen DA, Kennedy BW (1984). Estimation of genetic variances from unselected and selected populations. J Anim Sci 59: 1213-1223.

Van der Werf JHJ, Boer IJM (1990). Estimation of additive genetic variance when base populations are selected. J Anim Sci 68: 3124-3132.

Verrier E, Colleau JJ, Foulley JL (1991). Methods for predicting response to selection in small populations under additive genetic models: a review. Livest Prod Sci 29: 93-114.

Zobel B, Talbert J (1984). Applied Forest Tree Improvement. Wiley: New York. 